\title{
PERCEPÇÕES SOBRE A PROBLEMÁTICA SOCIOAMBIENTAL DA CIDADE DE BOM JESUS - RN
}

\author{
Diego Salomão C. de O. Salvador ${ }^{1}$ e Valdenildo Pedro da Silva ${ }^{2}$ \\ ${ }^{1}$ Graduando do Curso de Licenciatura em Geografia do CEFET-RN \\ diegolisse@yahoo.com.br \\ ${ }^{2}$ Professor do CEFET-RN, Doutor em Geografia \\ valdenildo@cefetrn.br
}

Recebido em janeiro de 2006 e aceito em maio 2006

\begin{abstract}
RESUMO
As cidades têm conquistado um lugar sem precedentes na história, transformando-se na expressão máxima da sociedade contemporânea. Atualmente, nas cidades concentram-se parcelas significativas da população e imensas contradições, que fazem com que elas sejam marcadas também com o que as sociedades têm de melhor e de pior. Além da riqueza, do acesso privilegiado à informação, dos fluxos econômicos, dentre outros, observam-se também as mais intensas manifestações de poluição, violência, pobreza e exclusão, apontando para a gravidade das questões de ordem social que imperam nesse espaço. Além do mais, não se pode negligenciar o fato de que as mais importantes questões socioambientais ocorrem nas cidades, pois aí estão as maiores concentrações populacionais e atividades econômicas com importantes desdobramentos para a vida urbana. Desse modo, a discussão socioambiental contemporânea deve priorizar essa ordem, a da cidade. Com isso, faz-se, não somente necessário, como também urgente, a busca de novos olhares sobre a problemática socioambiental urbana, bem como a socialização de práticas eficazes referentes a essa problemática. Assim, o objetivo deste trabalho é desvendar as percepções, os desafios e as possibilidades de superação dos problemas socioambientais da pequena cidade de Bom Jesus, situada no interior do Estado do Rio Grande do Norte. Este estudo foi desenvolvido por meio de uma pesquisa qualitativa, utilizando-se alguns procedimentos, como a pesquisa bibliográfica e a empírica, a qual foi realizada com alguns segmentos da sociedade local. Os resultados e conclusões obtidos até o momento, a partir das percepções dos moradores locais, apontam para problemas socioambientais de grandes dimensões, como os que foram mencionados acima, mas também para outros próprios da realidade local. O estudo também atenta para algumas reflexões que valorizam a construção de uma sociedade sustentável, do ponto de vista material e espiritual.
\end{abstract}

Palavras-chave: problemas socioambientais, vivência da população, qualidade de vida.

\section{PERCEPTIONS ON THE SOCIOENVIRONMENTAL PROBLEMATIC IN THE CITY OF BOM JESUS-RN}

\begin{abstract}
The cities have conquered a place without precedents in history, changedding themselves into the maximum expression of the society contemporary. Currently, in the cities significant parcels of the population and immense contradictions are concentrated, that make with that they are also marked with what the societies have of better and of worse.
\end{abstract}


Beyond the wealth, of the privileged access to the information, of the economic flows, amongst others, the most intense manifestations of pollution, violence, poverty and exclusion are also observed, pointing with respect to the gravity of the questions of social order that reign in this space. In addition, if it cannot neglect the fact of that the most important socioenvironmental questions occur in the cities, therefore are the biggest population concentrations and economic activities with important unfoldings for the urban life there. In this way, the socioenvironmental quarrel contemporary must prioritize this order, of the city. With this, one becomes, not only necessary, as also urgent, the search of new looks on the problematic urban socioenvironmental, as well as the socialization of practical efficient referring to this problematic one. Thus, the objective of this work is to unmask the perceptions, the challenges and the possibilities of overcoming of the socioenvironmental problems of the small city of Bom Jesus, situated in the interior of the State of the Rio Grande do Norte. This study it was developed by means of a qualitative research, using some procedures, as the bibliographical research and the empiricist, which was carried through with some segments of the local society. The results and conclusions until the moment, from the perceptions of the local inhabitants, point with respect to socioenvironmental problems of great dimensions, as the ones that had been mentioned above, but also for other proper ones of the local reality. The also intent study for some reflections that value the construction of a sustainable society, of the material and spiritual point of view.

Keywords: socioenvironmental problems, experience of the population, quality of life. 


\section{PERCEPÇÕES SOBRE A PROBLEMÁTICA SOCIOAMBIENTAL DA CIDADE DE BOM JESUS - RN}

\section{PALAVRAS INICIAIS}

O presente estudo traz algumas discussões sobre os problemas socioambientais existentes na cidade de Bom Jesus, localizada no interior norte-rio-grandense (mapa 01). São realizadas algumas reflexões oportunas sobre os problemas socioambientais bonjesusenses, através das percepções dos moradores locais, tendo-se em vista o que esses problemas significam para a sociedade de Bom Jesus, o que está sendo feito e o que poderia fazer-se para dar início à superação dos agravos socioambientais existentes na cidade.

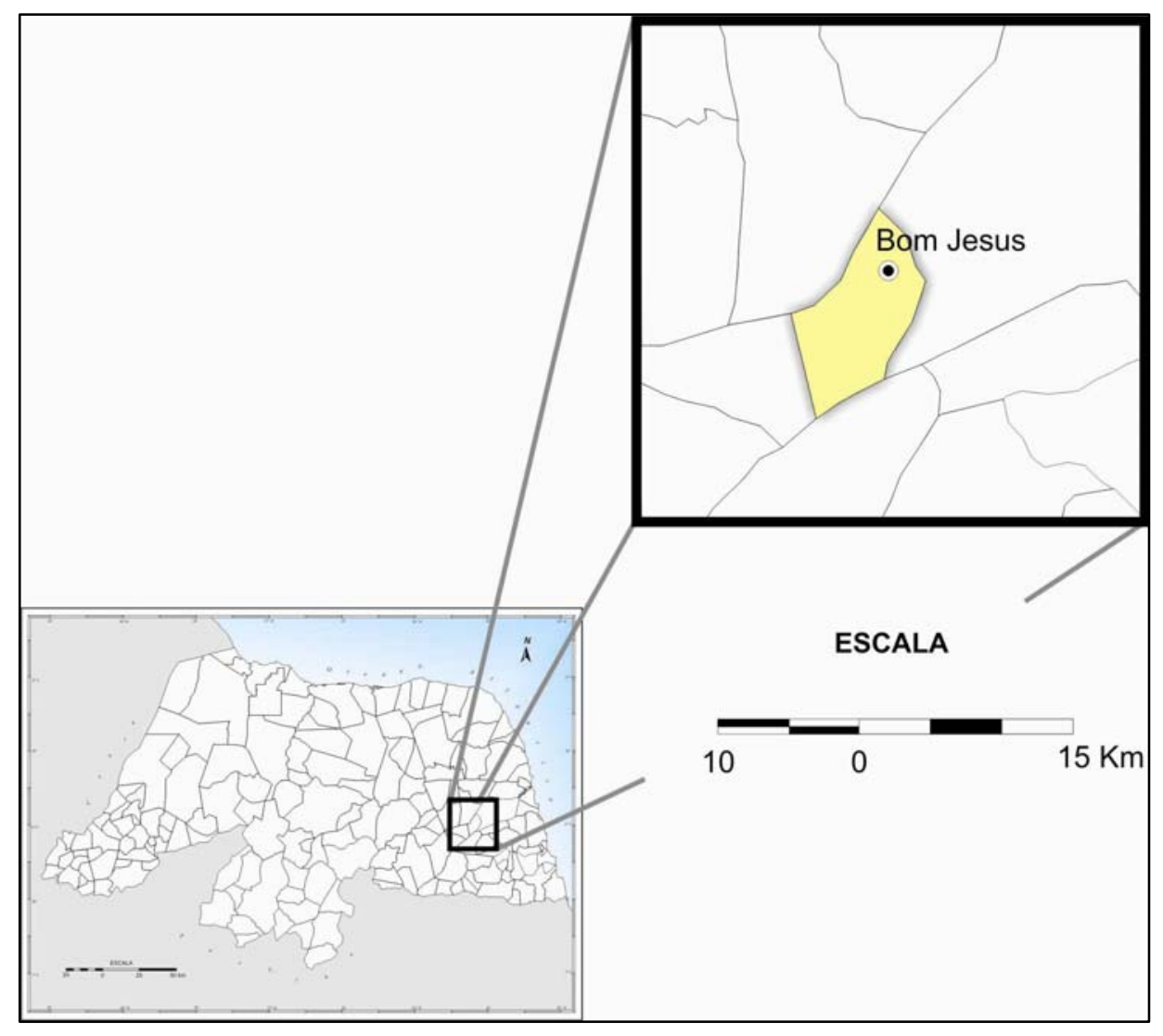

Mapa 1 - Localização do município de Bom Jesus no Rio Grande do Norte Nota: Organização: Valdenildo Pedro da Silva, 2006.

Cartografia: Josué Alencar Bezerra, 2006.

Inicialmente, é válido tecer alguns comentários sobre os problemas socioambientais urbanos. Para isso, vale lembrar que as cidades têm conquistado um lugar sem precedentes na história, transformando-se na expressão máxima da sociedade contemporânea. Nelas, concentram-se parcelas significativas da população mundial e imensas contradições, as quais permitem afirmar que aí se encontra o que as sociedades têm de melhor e de pior. Além da riqueza, do acesso privilegiado a informações, dos fluxos econômicos, dentre outros, observam-se também as mais intensas manifestações de poluição, violência, pobreza e exclusão, apontando para a gravidade das questões de ordem social que imperam nesse espaço. 
Com isso, não se pode negligenciar o fato de as mais graves questões socioambientais ocorrerem nas cidades, pois aí estão as maiores concentrações populacionais e de atividades econômicas, o que gera importantes desdobramentos para a vida sócio-urbana. Pode-se dizer, assim, que as discussões contemporâneas acerca dos problemas socioambientais devem priorizar a ordem das cidades, as quais são definidas por Santos (2003) como sendo espaços representativos da resistência social.

Os problemas socioambientais urbanos são cada vez mais estudados nos meios acadêmicos e debatidos nos meios populares, em âmbito mundial. Isso ocorre em função de, infelizmente, eles estarem presentes, praticamente, em todas as comunidades mundiais. Harvey (2004) declara que, com a evolução das perspectivas sociais, econômicas e políticas mundiais, esses problemas passaram a ser pensados e debatidos, com veemência, em escala global. Entretanto, a análise em tela procurou refletir sobre esses problemas no âmbito do lugar, isto é, de um pequeno espaço urbano.

Nas discussões deste texto, tomou-se como ancoragem as palavras de Silva (1999), quando defende que não se pode separar cartesianamente o homem da natureza, porque aquele é, indiscutivelmente, interligado a esta. A partir desse raciocínio, diz-se que, sempre que aqui se debaterem os problemas ambientais, se estará, ao mesmo tempo, refletindo sobre o social. Nessa perspectiva, torna-se eficaz o uso do termo "problemas socioambientais".

No decorrer do texto, são apresentados os resultados de uma pesquisa empírica realizada com a população bonjesusense, que apontou os problemas socioambientais de sua cidade. Foi importante o reconhecimento dos problemas da cidade ter sido feito pela própria população. Isso se coaduna com o pensamento de Thiollent (1994, p.67) quando declara que “[...] o saber popular é rico, espontâneo e muito apropriado à situação local”, sendo também fundamental para as investigações científicas. Além do mais, Diegues (1992) defende que, se os problemas socioambientais forem percebidos pelo povo, um grande passo para a resolução deles já terá sido dado.

A pesquisa empírica envolveu cinqüenta moradores locais. Estes foram selecionados a partir de segmentos sociais, sendo consultados funcionários públicos, comerciantes, políticos, agricultores, professores, donas de casa, sindicalista, aposentados, dentre outros. Prezou-se, na pesquisa, pelo qualitativo, privilegiando-se as falas dos atores sociais da cidade. Convém ressaltar que isso não significou a desconsideração do quantitativo. Pelo contrário, quando necessário, foram utilizados dados quantitativos para ratificar os argumentos presentes no estudo em tela, articulando-se estes aos aspectos qualitativos.

Como objetivo maior do estudo, pretendeu-se desvendar as percepções ${ }^{1}$, os desafios e as possibilidades $^{2}$ de superação dos problemas socioambientais da cidade, contribuindo, assim, para que a sociedade bonjesusense possa buscar melhores condições de vida, através da superação dos problemas que vivencia. Para se atingir esse objetivo, procurou-se: conhecer os problemas socioambientais existentes em Bom Jesus, a partir das falas dos habitantes locais; analisar criticamente esses problemas; subsidiar cientificamente o

\footnotetext{
${ }^{1}$ Segundo Tuan (1980, p. 04), "percepção é [...] a resposta dos sentidos aos estímulos externos".

${ }^{2}$ Possibilidade, de acordo com Abbagnano (1982), vem de possível, que é tudo aquilo que pode ou não ser. O autor destaca o pensamento de Aristóteles (p. 746) sobre possibilidade, quando declara que "o necessário deve ser possível, [...] porque, se não fosse, seria impossível”.
} 
desenvolvimento de políticas públicas que promovam a melhoria das condições de vida da população bonjesusense.

A seguir, serão discutidos os problemas socioambientais de Bom Jesus, atentando para os desafios que eles causam à sociedade local e para possibilidades de superação e/ou minimização desses problemas.

\section{AS PERCEPÇÕES DOS BONJESUSENSES SOBRE OS PROBLEMAS SOCIOAMBIENTAIS DA CIDADE E AS POSSIBILIDADES DE SUPERAÇÃO DESTES}

A cidade de Bom Jesus localiza-se a 46 quilômetros de Natal, capital do Rio Grande do Norte, tendo aproximadamente 9.492 habitantes (IBGE, 2006). Integra a mesorregião do Agreste Potiguar, possuindo as seguintes características fisiográficas: clima com características sub-úmidas, com precipitações que variam entre 800 e 1200 milímetros anuais; vegetação subcaducifólia, com características de transição entre a litorânea e a caatinga; relevo de baixas elevações - 98 metros (IDEMA, 2005) - fazendo parte da região de Tabuleiros Costeiros; formação geológica proveniente do período Cretáceo / Pleistocênico da Era Terciária (CARVALHO; FELIPE, 2004); e hidrografia marcada com a presença do Rio Jundiaí, efluente do Potengi, de lagoas e açudes com pequena capacidade de acumulação, e riachos. Segundo informações cedidas pelo IDEMA (2006), Bom Jesus não possui mananciais com qualidade e quantidade para o uso populacional, dependendo totalmente do abastecimento de água decorrente do Sistema Adutor Agreste / Trairí / Potengi.

A formação socioespacial da cidade se deu ancorada no transporte de gado do sertão (interior) para o litoral do estado, sendo que o espaço bonjesusense constitui-se como destinado à circulação de mercadorias, capitais e pessoas (FELIPE, 1988). Vale destacar que se compreende aqui o espaço como uma construção social, sendo o produto das relações que os homens mantêm entre si e com o seu meio (SAQUET et al, 2004).

Até 1962, Bom Jesus manteve-se atrelada, social, espacial e politicamente, a outros municípios do Rio Grande do Norte (Macaíba, Serra Caiada e Senador Elói de Souza). Nesse ano, mais precisamente no dia 11 de maio, foi declarada a emancipação política e, a partir de então, Bom Jesus passou a ser considerado um município norte-rio-grandense. Essa emancipação não foi obtida por meio de movimentos populares, mas fundamentada somente nos interesses políticos das classes dominantes locais.

Com a emancipação, as autoridades políticas passaram a investir na construção da infraestrutura sócio-urbana bonjesusense. Nisso, houve um grande desrespeito para com o meio natural da cidade. Para que houvesse a expansão socioespacial, essas autoridades julgaram que seria necessário alterar bruscamente as estruturas físicas naturais da cidade. Um triste exemplo é o da Lagoa das Panelas, a qual tem íntima relação com os aspectos socioculturais e históricos bonjesusenses.

Essa lagoa, em função de sua localização próxima da BR 226, que passa pela cidade, sofreu inúmeros aterramentos, para a construção de prédios públicos e casas populares no espaço ocupado por ela. Os aterramentos foram tão intensos que, por meio de medição 
feita in loco, detectou-se que hoje a lagoa ocupa apenas metade da área ${ }^{3}$ que ocupava até 1976, ano em que começaram os aterramentos. Além desse caso, outros referentes a desmatamentos, poluição e outras tantas agressões socioambientais poderiam ser destacados aqui como decorrentes da desorganizada expansão socioespacial de Bom Jesus. Corrêa (2001, p. 13) frisa que "a urbanização, acelerada e desorganizada, [...] [provoca] inúmeros impactos [socio]ambientais”.

Analisando o caso da lagoa, vê-se que os problemas socioambientais estão presentes na cidade desde o início de sua formação socioespacial e política. Além disso, pode-se dizer que a população sempre esteve à parte do processo de construção socioespacial de Bom Jesus, revelando certa submissão às classes dirigentes locais. Assim sendo, resolveu-se mudar essa situação, através da consulta direta sobre as percepções dos habitantes de Bom Jesus em relação aos problemas socioambientais locais. Isso foi feito porque se acredita que a população deve ter participação direta nas discussões acerca dos problemas socioambientais urbanos, até porque é a mais afetada por esses problemas.

Para tanto, foram realizadas entrevistas com moradores da cidade, durante os meses de junho e julho de 2005. Das pessoas consultadas, 32 eram homens e 18 mulheres.

O Gráfico 1 traz dados sobre o grau de instrução dos entrevistados. Nele observa-se que 8\% deles declararam nunca ter estudado ou ter estudado muito pouco, 32\% estudam ou já estudaram o Ensino Fundamental, 28\% cursam ou já cursaram o Ensino Médio e 32\% estudam ou estudaram o Ensino Superior. Vê-se, pela diversidade do grau de instrução dos entrevistados, que se buscou uma multiplicidade de pensamentos, para que os problemas da cidade fossem percebidos pelas mais diversas classes sociais locais.

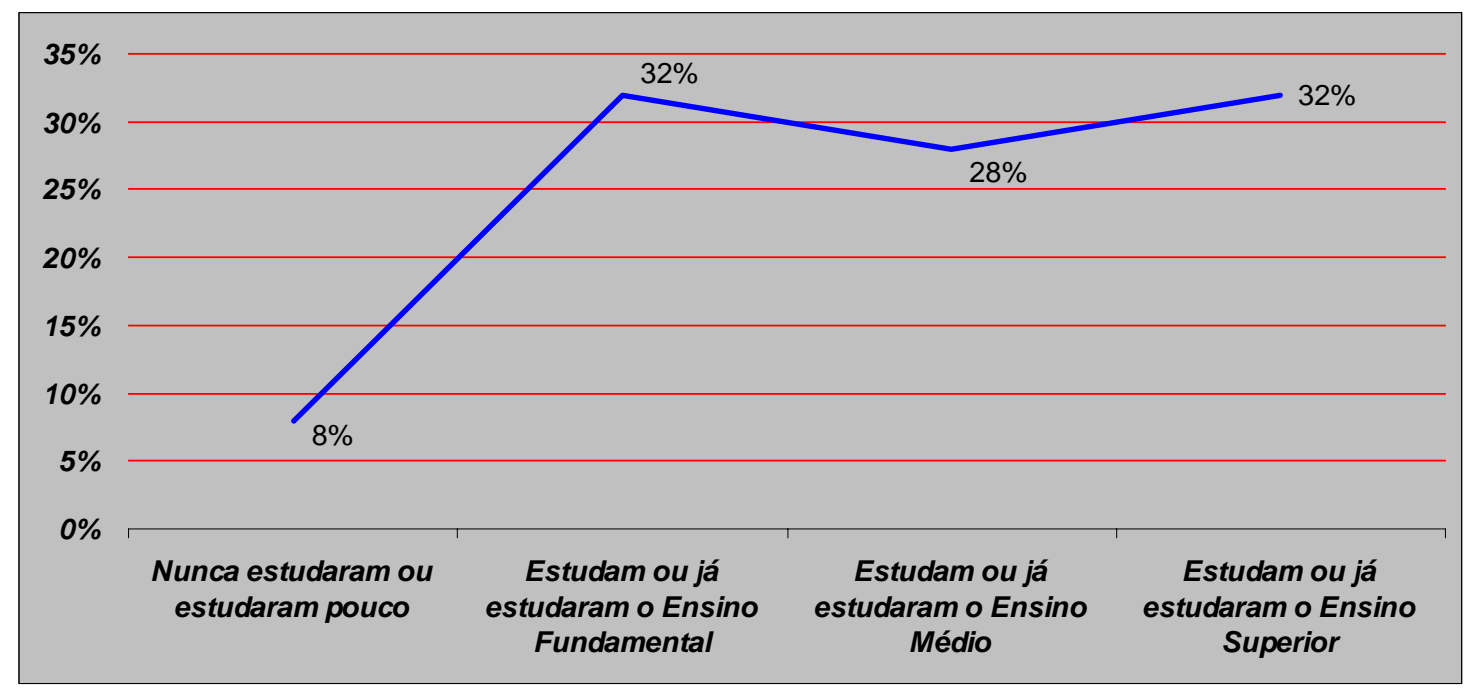

Gráfico 1 - Grau de instrução dos entrevistados

Fonte: Pesquisa de Campo, 2005.

No Gráfico 2, destaca-se a renda familiar dos entrevistados, mostrando-se que 32\% deles ganham de um até dois salários mínimos, 34\% recebem mensalmente de três a quatro

\footnotetext{
${ }^{3}$ Até 1976, quando os aterramentos começaram, a Lagoa possuía 35.270,04 $\mathrm{m}^{2}$ de área. Hoje, possui apenas $18.277,60 \mathrm{~m}^{2}$, ou seja, aproximadamente, metade do que possuía anteriormente.
} 
salários e outros 34\% ganham mais de quatro salários. Esses dados revelam a diversidade buscada, até mesmo na distribuição de renda, dos habitantes consultados.

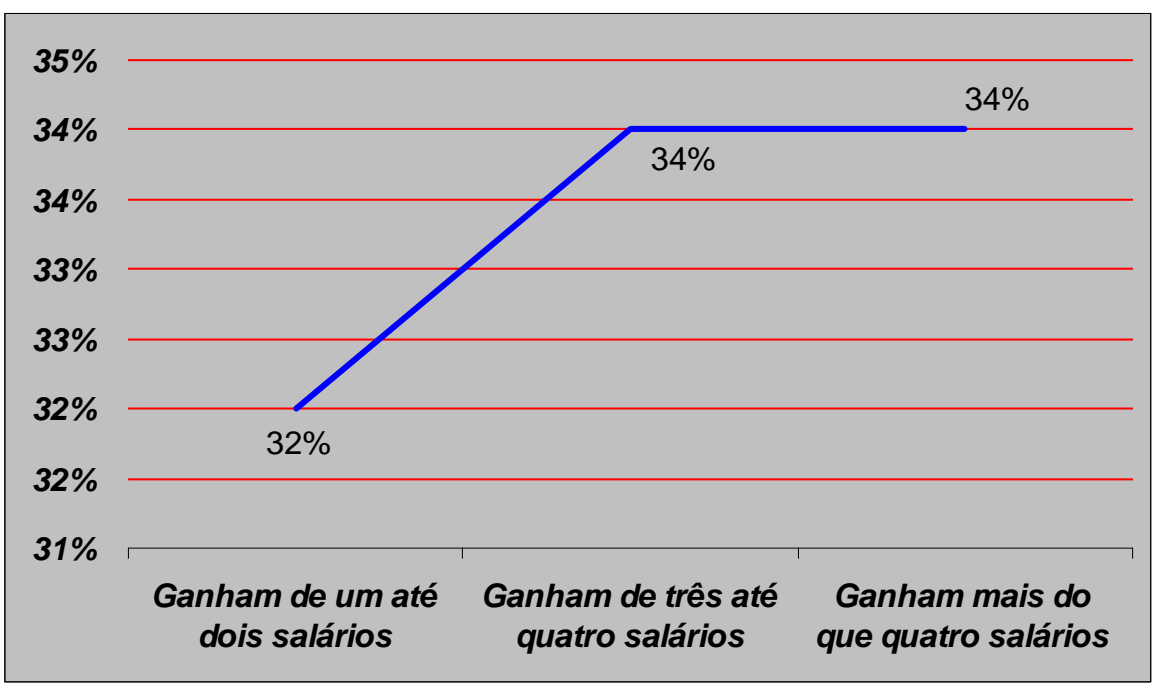

Gráfico 2 - Renda familiar dos entrevistados

Fonte: Pesquisa de Campo, 2005.

Já no Gráfico 3, mostra-se o tempo de residência na cidade dos moradores consultados. Destes, $40 \%$ moram na cidade há até 30 anos, 44\% moram de 30 até 50 anos, $14 \%$ de 50 a 70 anos e $2 \%$ já residem em Bom Jesus há mais de 70 anos. Fica explícito, portanto, que se atentou para o questionamento de moradores já bastante antigos no local. Assim, teve-se a informação de que os problemas socioambientais em Bom Jesus não datam de agora. Isso se evidencia pelas palavras de Andrade (1999) quando afirma que os problemas socioambientais não resultam apenas da conjuntura contemporânea, mas representam o coroamento de processos evolutivos desrespeitosos à natureza, ou seja, ao próprio homem.

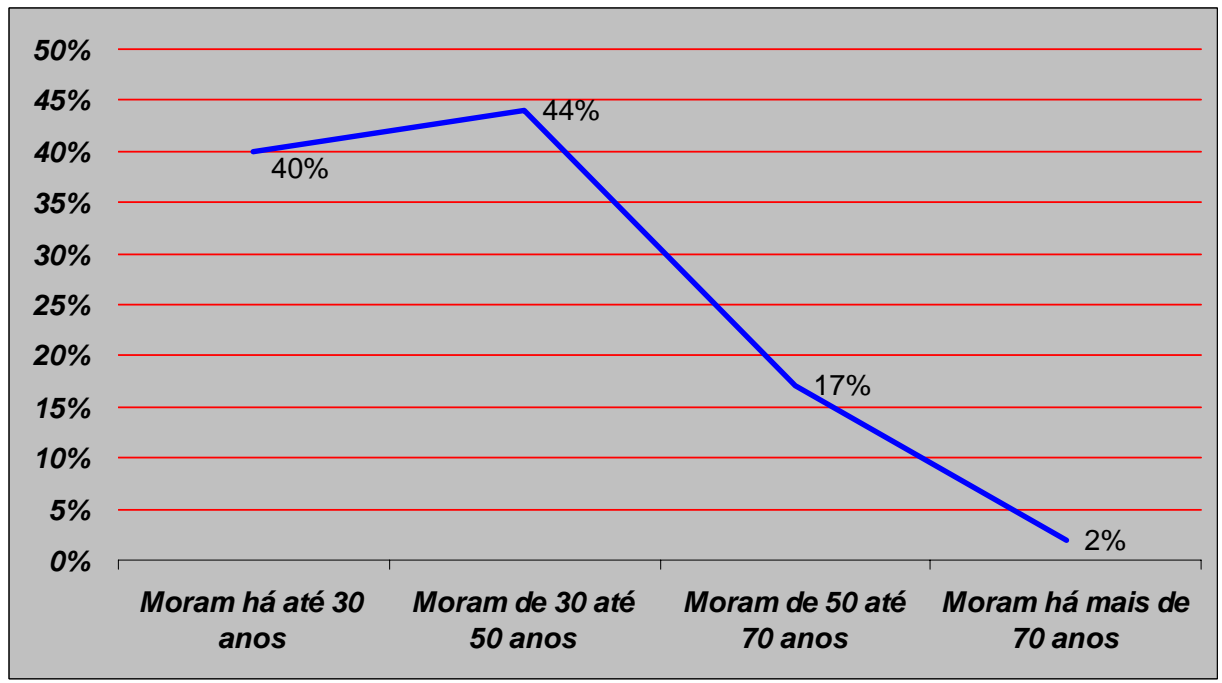

Gráfico 3 - Tempo de residência dos entrevistados na cidade de Bom Jesus-RN Fonte: Pesquisa de Campo, 2005.

Após a caracterização pessoal de cada entrevistado, foram-lhe dirigidas quatro perguntas. A primeira questionava se Bom Jesus era um lugar bom para se viver. A maioria dos entrevistados (90\%) respondeu que sim e uma minoria (10\%) disse que não. Aqueles que responderam positivamente justificaram a resposta referindo-se à tranqüilidade ainda 
existente na cidade, à amizade que há entre os moradores, à natividade, à presença familiar na cidade, às oportunidades de sobrevivência, ao clima agradável do local, à sua boa localização (próxima da capital do estado), à existência de abastecimento de água e luz e ao fato de existir na cidade comércios e feira bastante sortidos. Sobre essa pergunta, o viceprefeito municipal disse que Bom Jesus é, sim, um bom lugar para se viver, "porque é próxima da capital e é boa para mim em questões econômicas [...]”. Essa resposta, infelizmente, revela um tom individualista dessa autoridade local, a qual deveria pensar, prioritariamente, de forma coletiva.

Já aqueles que disseram que Bom Jesus não é um bom lugar para se viver atribuíram isso à falta de infra-estrutura social na cidade. Vale frisar que a maioria dos entrevistados disse que a cidade seria ótima para nela se viver, desde que houvesse oportunidades empregatícias para toda a população. Pelo visto, a falta de emprego é um grave problema que aflige a população local.

A segunda pergunta interrogou se na cidade existem problemas que afetam a qualidade de vida da população. Uma maioria esmagadora (96\%) disse que existem múltiplos problemas que prejudicam a qualidade de vida da população local. Entre os mais citados, pode-se destacar a falta de empregos, a precariedade do sistema de segurança local, a insuficiência dos serviços de saúde e educação fornecidos, a inexistência de tratamento de esgotos, a falta de políticas socioambientais e a acentuada pobreza da maioria da população. $\mathrm{O}$ atual Secretário Municipal de Administração, quando consultado, disse que Bom Jesus possui "inúmeros" problemas, como, por exemplo, "a falta de planos gestores e de políticas ambientais”. Percebe-se que a própria classe dirigente municipal reconhece os problemas existentes e revela a sua incapacidade de formular planos gestores e de tomar atitudes que venham a combater os problemas locais.

Os que disseram não existir problemas em Bom Jesus (4\%) destacaram que os habitantes que não trabalham em postos empregatícios públicos ou privados têm procurado, na maioria das vezes, a agricultura para garantir sua subsistência. Todavia, infelizmente, essa minoria esquece que a concentração fundiária é mais um grave problema existente localmente.

Antes de prosseguir para o terceiro questionamento, é necessário dizer que os problemas apontados constituem-se em desafios para a população, dificultando o alcance da desejável sustentabilidade, a qual cada sociedade procura e alcança de modo particularizado (DIEGUES, 1992). Esses problemas são tidos por alguns moradores como naturais, ou seja, decorrentes da expansão socioespacial da cidade. Isso fica evidente nas palavras de uma professora das redes municipal e estadual de ensino no local, quando diz que "com o passar do tempo, a cidade cresceu e isso trouxe consigo malefícios para esta”. Entretanto, defende-se aqui que os problemas socioambientais bonjesusenses são um reflexo da incapacidade política das autoridades locais e também do descaso participativo dos habitantes da cidade para com os problemas nela existentes.

A terceira pergunta questionou a existência ou não de algum programa governamental que vise preservar o meio ambiente local. A maioria dos entrevistados (84\%) respondeu que não há nenhum programa governamental na cidade com esse intuito. Alguns integrantes dessa maioria fizeram questão de deixar explícito o pouco interesse das autoridades políticas locais para com a preservação do meio ambiente, tanto que um ex-prefeito municipal declarou que "os políticos não ligam para assuntos sobre o meio ambiente”. Os 
que responderam positivamente (16\%) destacaram o papel da Prefeitura Municipal ao tentar manter a limpeza das ruas da cidade como fator justificador de suas respostas.

Por fim, foi perguntado aos entrevistados se eles colaboram para preservar a qualidade do meio ambiente da cidade. Sem exceção, todos declararam que sim, que colaboram através da preocupação em manusear corretamente o lixo e de não jogá-lo nas ruas, em não desperdiçar água e não derrubar ou destruir árvores. Alguns moradores também se predispuseram a colaborar mais, se iniciativas públicas fossem tomadas em relação a esse assunto.

Infelizmente, ficou evidente, através da análise das respostas à última pergunta, que a maioria da sociedade bonjesusense não pensa em realizar atos coletivos que possam despertar a discussão de soluções para os problemas socioambientais da cidade. Isso é confirmado quando um funcionário público municipal aposentado diz que colabora imensamente para preservar o meio ambiente local “mantendo a frente da casa limpa”. É claro que aqui se concorda que, em relação aos assuntos ambientais, atitudes isoladas podem explicar grandes acontecimentos. Ou seja, não se discorda de que quando se mantém a frente da própria casa limpa se está colaborando para a qualidade do meio ambiente local. Todavia, é necessário ter a consciência de que só isso não basta. Para alguns autores, como Jacobi (1999), os problemas socioambientais só serão solucionados se a população, em conjunto com as autoridades, tomarem atitudes rápidas e significativas. Jogar toda a culpa nos políticos, como faz a maioria da população bonjesusense, é fácil, mas os habitantes locais, como também os de outras cidades, devem se conscientizar de que a resolução dos problemas socioambientais urbanos envolve diversos atores, como os do povo, do governo, das instituições privadas e não-governamentais, dentre outros.

Defende-se, ainda, seguindo as concepções de Jacobi (1999), que a população bonjesusense necessita ter acesso à educação ambiental, o que proporcionaria conhecimento sobre as responsabilidades que cada um tem na resolução dos problemas citadinos. Além disso, através da educação ambiental, pode-se despertar a participação popular, de forma direta e consciente, na resolução dos problemas socioambientais, o que é imprescindível.

\section{REFLEXÕES FINAIS}

Ao fim das considerações sobre os problemas socioambientais, particularmente os de Bom Jesus, conclui-se que a resolução e/ou minimização destes deve estar atrelada à participação direta e consciente de toda a sociedade.

Além disso, pode-se dizer que os problemas percebidos pelos bonjesusenses, como, por exemplo, falta de emprego, inexistência de rede de tratamento de esgotos, segurança pública precária, educação e serviços de saúde de má qualidade, dentre outros, são uma reflexão do descaso social e político existente no local. Os habitantes e as autoridades da cidade, em sua maioria, pensam e agem individualmente, de acordo com os próprios interesses, desconsiderando o meio ambiente.

O caminho para a solução dos problemas socioambientais bonjesusenses fica aqui explicitado: compromisso populacional e político em relação aos assuntos socioambientais. 
Para tanto, faz-se necessário uma mudança das concepções e atitudes ${ }^{4}$ individuais dos habitantes e políticos locais para as coletivas, pelo menos em relação ao meio ambiente, o que pode ser obtido a partir do desenvolvimento de uma atitude ética e de práticas de educação ambiental que estejam ao alcance de todos. Acontecendo isso, espera-se que a sociedade bonjesusense encontre o seu próprio caminho para a sustentabilidade.

Em suma, encerrando as discussões deste texto, é importante destacar que os problemas socioambientais, infelizmente, não integram apenas a realidade social bonjesusense, nem mesmo são menos intensos em outras realidades. Isso fica evidente quando se analisa a fala de um jovem agricultor que reside em Bom Jesus, quando diz: "apesar de todos os problemas que a cidade possui, de todas as que eu morei, esta é a melhor”.

\section{REFERÊNCIAS}

ABBAGNANO, N. Dicionário de filosofia. São Paulo: Mestre Jou, 1982.

ANDRADE, M. C. de. A produção do espaço norte-rio-grandense. Natal: Cooperativa Cultural (UFRN), 1990.

CARVAlHO, E. A. de; FELIPE, J. L. A. Atlas do Rio Grande do Norte. Natal: Diário de Natal, 2004.

CORRÊA, R. L. Pensando a Geografia brasileira do começo do século XXI. Sociedade e Território, Natal, jul./dez. 2001.

DIEGUES, A. C. S. Desenvolvimento sustentável ou sociedades sustentáveis: da crítica dos modelos aos novos paradigmas. São Paulo em Perspectiva, São Paulo, v. 6, n. 1-2, p. 22-29, jan./jun. 1992.

FELIPE, J. L. Elementos de Geografia do Rio Grande do Norte. Natal: EDUFRN, 1988.

HARVEY, D. Espaços de esperança. São Paulo: Loyola, 2004.

IBGE (Instituto Brasileiro de Geografia e Estatística). Censo demográfico. Disponível em: <http://www.ibge.gov.br/cidadesat/default.php>. Acesso em: 23 jan. 2006.

IDEMA (Instituto de Desenvolvimento Econômico e Meio Ambiente do Rio Grande do Norte). Perfil do seu município: Bom Jesus. Natal, 2005.

JACOBI, P. Cidade e meio ambiente: percepções e práticas em São Paulo. São Paulo: AnnaBlume, 1999.

SANTOS, M. Por uma outra globalização: do pensamento único à consciência universal. Rio de Janeiro: Record, 2003.

SAQUET, M. A. et al. Paisagem, espaço e território. Formação, Presidente Prudente, v. 1, n. 11. 2004.

SILVA, V. P. da. Problemática socioambiental: um estudo sobre a indústria ceramista em Carnaúba dos Dantas/RN. Sociedade e Território, Natal, jul./dez. 1999.

THIOLLENT, M. Metodologia da pesquisa-ação. São Paulo: Cortez, 1994.

TUAN, Y. F. Topofilia: um estudo da percepção, atitudes e valores do meio ambiente. São Paulo: Difel, 1980.

\footnotetext{
${ }^{4}$ Atitude é primariamente uma postura cultural, uma posição que se toma frente ao mundo. Ela [...] é formada de uma longa sucessão de percepções, isto é, de experiências. [...] As atitudes implicam experiência e uma certa firmeza de interesse e valor” (TUAN, 1980, p. 04).
} 